\title{
Expression of Genes Related to Glycolysis in the Liver and Skeletal Muscle of Rats after Citric Acid Administration
}

\author{
Yurie Hara1, Nakamichi Watanabe ${ }^{2 *}$ \\ ${ }^{1}$ Department of Nutritional Science, Tokyo Kasei University, Tokyo, Japan \\ ${ }^{2}$ Department of Health Science, Showa Women’s University, Tokyo, Japan \\ Email: ^nakamich@swu.ac.jp
}

How to cite this paper: Hara, Y. and Watanabe, N. (2019) Expression of Genes Related to Glycolysis in the Liver and Skeletal Muscle of Rats after Citric Acid Administration. Food and Nutrition Sciences, 10, 325-332.

https://doi.org/10.4236/fns.2019.103025

Received: February 27, 2019

Accepted: March 23, 2019

Published: March 26, 2019

Copyright $\odot 2019$ by author(s) and Scientific Research Publishing Inc. This work is licensed under the Creative Commons Attribution International License (CC BY 4.0).

http://creativecommons.org/licenses/by/4.0/

\begin{abstract}
Citric acid is known to alleviate physical fatigue and improve athletic performance; however, the underlying mechanism is unknown. Therefore, we aimed to investigate the effect of citric acid administration on the expression of key glycolysis-related genes in the liver and skeletal muscle of rats. Eight-week-old male Sprague-Dawley rats were divided into two groups-control and citric acid groups. The rats were fasted overnight, after which distilled water or citric acid solution was administered intragastrically; after $150 \mathrm{~min}$, the rats were sacrificed, and the liver and skeletal muscle were collected. In the skeletal muscle, namely soleus and gastrocnemius muscles, the phosphofructokinase and pyruvate kinase gene expression were significantly decreased by citric acid administration. In contrast, the glucokinase and pyruvate kinase gene expression in the liver was significantly increased. These results suggest that exogenous dietary citric acid suppresses glycolysis in the skeletal muscle at the transcription level.
\end{abstract}

\section{Keywords}

Citric Acid, Gastrocnemius Muscle, Glycolysis, Liver, Soleus Muscle

\section{Introduction}

Citric acid or sodium citrate is one of the organic acids present in citrus fruits such as lemon and orange. Its administration before or after exercise alleviates physical fatigue and improves athletic performance [1] [2] [3] [4] [5]. In addition, intake of citric acid is effective in alleviating daily fatigue [6]. Moreover, a randomized, double-blind, placebo-controlled, and cross-over study revealed that citric acid intake before low-intensity exercise attenuates physical fatigue 
and the feeling of fatigue [7]. In Japan, 15 kinds of foods containing citric acid are registered as "Foods with functional claims"1.

Further, the preference for citric acid in rats increased after forced swimming, whereas that for other acids such as hydroxyl chloride and maleic acid did not [8] [9].

However, the fatigue alleviation mechanism of citric acid or sodium citrate has not been elucidated. Previous studies have suggested the following hypotheses. 1) Dietary citric acid accelerates glycogen restitution after exercise by the suppression of phosphofructokinase (PFK) activity and the subsequent suppression of glycolysis [10]. This hypothesis was based on in vitro studies using purified PFK from the liver [11] [12] and skeletal muscle [13] [14] in rats. However, the effect of exogeneous dietary citric acid on PFK activity has not been clearly demonstrated. In addition, there are no reports on whether exogenous dietary citric acid suppresses the expression of Pfk at the transcription level. 2) Dietary citric acid accelerates gluconeogenesis accompanied by an increase in the phosphoenolpyruvate carboxykinase (Pck) mRNA levels [15] [16] in the skeletal muscle. However, further validation is needed because the increase in Pck mRNA expression has been demonstrated only in the skeletal muscle but not in the liver, although gluconeogenesis occurs in the liver. In addition, these results have been obtained using DNA microarrays, which are known to have weak reproducibility. 3) Dietary citric acid enters the mitochondria and activates the tricarboxylic acid cycle, thereby, increasing ATP production [5]. However, there are no reports suggesting that dietary citric acid can enter the mitochondria directly. Furthermore, a transporter of citric acid from the cytoplasm to the mitochondria has not been reported. 4) Dietary sodium citrate has buffering capacity and prevents hydrogen ion accumulation in the muscle during high-intensity exercise [1] [2] [3]. However, there is no evidence regarding the relationship between the blood $\mathrm{pH}$ and fatigue. Thus, these hypotheses have not been validated adequately, and only a few studies have focused on dietary citric acid function in the past 30 years [17].

In the present study, we assessed the expression of key glycolysis-related genes in the liver and skeletal muscle of rats after citric acid administration in order to validate the hypothesis that exogenous dietary citric acid can suppress glycolysis at the transcription level. Our study will lay a foundation for further studies on elucidation of the fatigue alleviation mechanism of citric acid.

\section{Materials and Methods}

\subsection{Animals, Experimental Diet, and Protocol}

Eight-week-old male Sprague-Dawley rats were purchased from Charles River Laboratories (Yokohama, Japan). The rats were housed in individual plastic cages at $21^{\circ} \mathrm{C} \pm 2{ }^{\circ} \mathrm{C}$ with a 12-h light-dark cycle (light interval was from 6:00 to 18:00 h). After taming for one week on the commercial non-purified chow diet ${ }^{1}$ http://www.caa.go.jp/policies/policy/food_labeling/information/pamphlets/pdf/151224_1.pdf, 2015 (Mar 30, 2018) 
(CRF-1; Charles River Laboratories), the rats were divided into two experimental groups, namely, control and citric acid groups. Each group contained seven rats, and the mean body weight of the two groups was equal. The rats were fasted overnight to eliminate the effects of food intake, and then distilled water or citric acid solution ( $66.6 \mathrm{mg} / 100 \mathrm{~g}$ body weight) was administered intragastrically using a probe. The dose of citric acid was the same as that in our previous studies [15] [16]. One hundred fifty minutes after administration, the rats were sacrificed by blood withdrawal from the abdominal aorta under isoflurane anesthesia. The duration of $150 \mathrm{~min}$ from citric acid administration to euthanasia was set to allow adequate time to alter gene expression because the plasma citric acid concentration is high at $120 \mathrm{~min}$. The blood glucose and lactate levels were measured, and the blood was centrifuged at $1900 \times \mathrm{g}$ for $10 \mathrm{~min}$ to obtain the plasma, which was stored at $-80^{\circ} \mathrm{C}$ until citric acid measurements. The liver and skeletal muscle were collected for glycogen analysis and stored at $-80^{\circ} \mathrm{C}$. A section $(0.5-\mathrm{cm}$ thick) of the liver, soleus muscle, and gastrocnemius muscle was immediately immersed into RNAlater (QIAGEN, Hilden, Germany) and stored at $-80^{\circ} \mathrm{C}$ until the measurement of mRNA levels. All animal studies were performed according to the approved animal research protocol of the Showa Women's University (approval number, 14-03).

\subsection{Measurement of the Blood Glucose, Blood Lactic Acid, and Plasma Citric Acid Levels}

The blood glucose and lactic acid levels were measured during blood collection using Medisafe Chips (Terumo, Tokyo, Japan) and Lactate Pro (Arkray, Kyoto, Japan), respectively. All measurements were performed in duplicates. The plasma citric acid level was measured by the modified method of Yasukawa et al. [18] [19]. Briefly, $500 \mu \mathrm{L}$ of $6 \%$ perchloric acid was added to $250 \mu \mathrm{L}$ plasma for deproteinization, and then the mixture was incubated at room temperature $\left(20^{\circ} \mathrm{C}-22^{\circ} \mathrm{C}\right)$ for $5 \mathrm{~min}$ and centrifuged $(10,000 \times \mathrm{g}, 5 \mathrm{~min})$. Subsequently, $500 \mu \mathrm{L}$ of the supernatant was neutralized with approximately $150 \mu \mathrm{L}$ of $2 \mathrm{M} \mathrm{KOH}$, and then $350 \mu \mathrm{L}$ of $1.2 \mathrm{M} \mathrm{KCl} / 1 \mathrm{M}$ Tris $\mathrm{HCl}$ buffer ( $\mathrm{pH}$ 8.6) was added and the mixture was centrifuged at $10,000 \times \mathrm{g}$ for $5 \mathrm{~min}$. Then, $500 \mu \mathrm{L}$ of the supernatant was mixed with $500 \mu \mathrm{L}$ of reagent $(0.04 \mathrm{mM} \mathrm{ZnSO} 4,0.3 \mathrm{mM} \beta$-NADH, $0.19 \mathrm{U}$ L-MDH (Roche Diagnostics, Indianapolis, USA)/1 M Tris $\mathrm{HCl}$ buffer $\mathrm{pH}$ 8.6) and the samples were incubated for $5 \mathrm{~min}$ at room temperature. The samples were then divided into two portions, and $20 \mu \mathrm{L}$ of solvent $(0.15 \mathrm{M}$ Tris $\mathrm{HCl}$ buffer $\mathrm{pH}$ 8.6) was added to one portion, whereas $20 \mu \mathrm{L}$ of citrate lyase $(0.15 \mathrm{U} \mathrm{CL}$ (Roche Diagnostics, Indianapolis, USA)/0.15 M Tris $\mathrm{HCl}$ buffer $\mathrm{pH}$ 8.6) was added to the other portion. The mixtures were incubated at room temperature for $20 \mathrm{~min}$. The plasma citric acid concentration was calculated from NADH consumption, which was determined from the difference in absorbance at $340 \mathrm{~nm}$ between the two samples measured using the U-5100 spectrophotometer (Hitachi High-Tech Science Co., Tokyo, Japan). 


\subsection{Measurement of Glycogen Content in the Liver and Skeletal Muscle}

The glycogen level in the liver and soleus muscle was measured by the phenol-sulfuric acid method. Briefly, $100 \mathrm{mg}$ of the liver or soleus muscle were homogenized in $0.8 \mathrm{~mL}$ of $10 \%$ trichloroacetic acid (Wako Pure Chemical Industries, Ltd., Osaka, Japan) and centrifuged at $1900 \times \mathrm{g}$ for $10 \mathrm{~min}$ ) to obtain a deproteinized supernatant. Then, $0.4 \mathrm{~mL}$ of this supernatant was mixed with $0.8 \mathrm{~mL}$ of $95 \%$ ethanol (Wako Pure Chemical Industries, Ltd.) and centrifuged at $1900 \times \mathrm{g}$ for $5 \mathrm{~min}$ to precipitate glycogen. The supernatant was removed by decantation and the precipitated glycogen pellet was re-suspended in $0.5 \mathrm{~mL}$ of distilled water. The re-suspended glycogen solution was mixed with $0.5 \mathrm{~mL}$ of $5 \%$ phenol (Wako Pure Chemical Industries, Ltd.) and $2.5 \mathrm{~mL}$ of concentrated sulfuric acid (Kanto Chemical Co., Inc., Tokyo, Japan), and incubated for 20 $\mathrm{min}$ at room temperature. The absorbance of the solution at $490 \mathrm{~nm}$ was measured. The standard curve was obtained using $40 \mathrm{mg} / \mathrm{L}$ glucose (Wako Pure Chemical Industries Ltd.) solution.

\subsection{RNA Extraction and Real-Time Reverse Transcription-Polymerase Chain Reaction}

The total RNA was isolated from the skeletal muscle (soleus and gastrocnemius muscles) and liver samples using RNeasy fibrous tissue mini kit and RNeasy mini kit (QIAGEN), respectively, according to the manufacturer's instructions. Reverse transcription was performed using PrimeScript RT reagent kit (Perfect real time; TaKaRa Bio, Shiga, Japan) to obtain the cDNA solution, which was stored at $-80^{\circ} \mathrm{C}$ until real-time polymerase chain reaction analysis for mRNA expression. Here, $10 \mathrm{ng}$ cDNA was used as the template for amplification reactions performed using the Power SYBR Green PCR Master Mix (Applied Biosystems, Foster City, CA, USA) and the Applied Biosystems 7500 RT-PCR system, according to the manufacturer's instructions. The reaction conditions were as follows: denaturation at $95^{\circ} \mathrm{C}$ for $10 \mathrm{~min}, 40$ cycles of denaturation at $95^{\circ} \mathrm{C}$ for $15 \mathrm{~s}$, and annealing/extension at $60^{\circ} \mathrm{C}$ for $1 \mathrm{~min}$. Table 1 lists the target genes and primer sequences. The expression of target genes was determined by the $\Delta \Delta \mathrm{Ct}$ method [20] using $\beta$-actin as the housekeeping gene.

Table 1. Primer sequences for real-teime PCR.

\begin{tabular}{lccc}
\hline \multicolumn{1}{c}{ Gene name } & Gene symbol & Forward Primers (5' to 3') & Reverse Primers (5' to 3') \\
\hline Liver & Gck & AGTATGACCGGATGGTGGATGAA & CCAGCTTAAGCAGCACAAGTCGTA \\
$\begin{array}{l}\text { Glucokinase } \\
\text { Phosphofructokinase }\end{array}$ & $P f k l$ & CCACCTGGAGGCCATTGATGA & GGGATGACGCACATGACGA \\
$\begin{array}{l}\text { Pyruvate kinase } \\
\text { Skeletal muscle }\end{array}$ & $P k l r$ & ATCTGGGCAGATGATGTGGA & ATAGGGTGTAACTGGGTCAGAATGG \\
Hexokinase 1 & & & \\
Phosphofructokinase & ATtGTCGCCGTGGTGAATGA & TAGCAAGCATTGGTGCCTGTG \\
Pyruvate kinase & $P f k m$ & GGGCTGACACAGCACTGAACA & GGCCAGATAGCCACAGTAACCAC \\
\hline
\end{tabular}




\subsection{Statistical Analysis}

All data were expressed as mean \pm standard error (SE). Statistical analyses were performed using GraphPad Prism7 (GraphPad Software, La Jolla, California, USA). The statistical significance $(\mathrm{p}<0.05)$ between the control and citric acid groups was evaluated by the Student's t-test.

\section{Results}

\subsection{Blood glucose, Blood Lactic Acid, and Plasma Citric Acid Levels}

The blood glucose and lactic acid levels in the control $(139 \pm 7 \mathrm{mg} / \mathrm{dL}$ and $2.0 \pm$ $0.1 \mathrm{mM}$, respectively) and citric acid groups $(145 \pm 8 \mathrm{mg} / \mathrm{dL}$ and $1.8 \pm 0.2 \mathrm{mM}$, respectively) were not significantly different. However, the plasma citric acid level in the citric acid group $(4.6 \pm 0.2 \mathrm{mg} / \mathrm{dL})$ was significantly higher than that of the control group $(3.0 \pm 0.1 \mathrm{mg} / \mathrm{dL})$.

\subsection{Glycogen Level in the Liver and Skeletal Muscle}

The liver glycogen level in the control and citric acid groups (42.4 \pm 6.4 and 55.8 $\pm 7.5 \mathrm{mg} / \mathrm{g}$, respectively) was not significantly different. Similarly, the glycogen level in the soleus muscle was not significantly different between the two groups (control group, $8.4 \pm 0.4 \mathrm{mg} / \mathrm{g}$; citric acid group, $8.6 \pm 0.3 \mathrm{mg} / \mathrm{g}$ ). The glycogen level in the gastrocnemius muscle was also not significantly different between the two groups (control group, $8.4 \pm 0.3 \mathrm{mg} / \mathrm{g}$; citric acid group, $9.0 \pm 0.4 \mathrm{mg} / \mathrm{g}$ ).

\subsection{Level of mRNA Expression in the Soleus Muscle, Gastrocnemius Muscles, and Liver}

The relative mRNA level of glycolysis-related genes in the soleus muscle is shown in Figure 1(a). Of the three genes coding for the rate-limiting enzymes of glycolysis, namely, hexokinase 1 ( $H k 1)$, phosphofructokinase $(P f k m)$, and pyruvate kinase $(P k m)$, the expression of $P f k m$ and $P k m$ in the citric acid group was significantly lower than that in the control group. The relative mRNA level of those

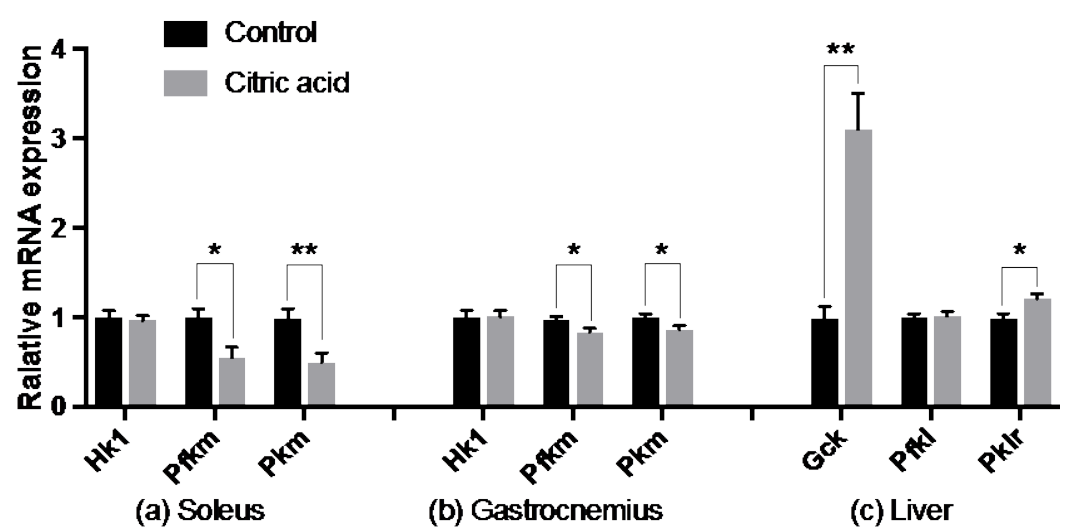

Figure 1. mRNA expression of genes related to glucose metabolism in the soleus muscle (a), gastrocnemius muscle (b), and liver (c). Data are presented as mean \pm SE of seven rats. The values are significantly different from the control group at ${ }^{\star} \mathrm{p}<0.05,{ }^{* *} \mathrm{p}<0.01$, and ${ }^{\star *} \mathrm{p}<0.001$. 
genes in the gastrocnemius muscle is shown in Figure 1(b). Similar to that in the soleus muscle, the expression of $P f k m$ and $P \mathrm{~km}$ in the citric acid group was significantly lower than that in the control group. The relative mRNA level is shown in Figure 1(c). Glucokinase (Gck), phosphofructokinase liver type (Pfkl), and pyruvate kinase L/R (Pklr), the expression of Gck and Pklr in the citric acid group was significantly higher than that in the control group. These results were different from those observed in the soleus and gastrocnemius muscles.

\section{Discussion}

Although citric acid has been implicated in reducing fatigue, the precise mechanism underlying such fatigue alleviation remains unclear. Therefore, to contribute to this aspect of research on citric acid, we investigated the expression of key glycolysis-related genes in the soleus muscle, gastrocnemius muscle, and liver of rats after citric acid administration. We demonstrated that citric acid administration suppressed the glycolysis-related genes $P f k m$ and $P k m$ in the soleus and gastrocnemius muscles. On the other hand, citric acid administration displayed opposite effects on the expression of the glycolysis-related genes Gck and Pklr in the liver.

Previous in vitro studies using the liver [11] [12] and skeletal muscle [13] [14] cells of rats reported that the supplementation of medium with citric acid inhibited the activity of PFK at the substrate level, indicating the suppression of glycolysis. Similarly, in the present study, focusing on transcription level in rats, the $P f k m$ expression in the soleus and gastrocnemius muscles was suppressed by citric acid administration. Compared with that of the other glycolysis-related genes, the expression of $\mathrm{Pkm}$ in the soleus and gastrocnemius muscles was also suppressed by citric acid administration, which is similar to that of Pfkm expression. These results suggest that citric acid administration suppresses glycolysis in the skeletal muscle not only at the substrate level but also at the transcription level.

In the liver, in contrast, citric acid administration increased the expression of the glycolysis-related genes Gck and Pfkl. In addition, previous studies reported that citric acid administration did not suppress the expression of glycolysis-related genes Gck, Pfkl, and Pklr, in the liver [15] [16]. Although the underlying mechanism contributing to these contradictory results in the skeletal muscle and liver cannot be elucidated yet, the discrepancy may be attributed to the difference in their citric acid and/or AMP concentrations. In an in vitro study using purified rat PFK, the enzyme was inhibited at 9.9 and $19.2 \mathrm{mg} / \mathrm{dL}(0.5$ and $1.0 \mathrm{mM}$ ) citric acid, compared with that in the untreated control [11] [13]. However, in the present study, the plasma citric acid concentration in the control and citric acid groups was 3.0 and $4.6 \mathrm{mg} / \mathrm{dL}$, respectively. The skeletal muscle PFK level might be affected by the small difference in citric acid concentration, whereas its liver form might exhibit different sensitivity to citric acid. In addition, because PFK is strongly activated by AMP and inhibited by ATP [11] [13], the association between plasma citric acid and AMP and/or ATP levels might have influenced the inhibition or activation of PFK after citric acid ad- 
ministration. However, as the above discussion was based on the results at the substrate level, further studies are warranted to clarify whether the substrate-level observations are applicable to the transcription level.

Unlike that in previous reports, in the present study, the glycogen content in the skeletal muscle did not increase after citric acid administration [10], whereas the expression of glycolysis-related genes was suppressed. This phenomenon might be induced by the differences in the citric acid administration conditions. In the present study, only citric acid was administered, whereas in the previous study, citric acid and glucose were co-administered [10].

\section{Conclusion}

The present study suggests that exogenous dietary citric acid suppresses glycolysis at the transcription level in rats. To elucidate the association between transcription level suppression of glycolysis and fatigue alleviation, further studies are needed. Furthermore, we propose that different approaches involving different organs are essential for future studies on functional food components because opposite effects were observed in the expression of some genes in the liver and skeletal muscle.

\section{Acknowledgements}

This study was supported by JSPS KAKENHI Grant Number JP 25750054.

\section{Conflicts of Interest}

The authors declare that they have no conflicts of interest.

\section{References}

[1] McNaughton, L. and Cedaro, R. (1992) Sodium Citrate Ingestion and Its Effects on Maximal Anaerobic Exercise of Different Durations. European Journal of Applied Physiology and Occupational Physiology, 64, 36-41. https://doi.org/10.1007/BF00376437

[2] Hausswirth, C., Bigard, A.X., Lepers, R., Berthelot, M. and Guezennec, C.Y. (1995) Sodium Citrate Ingestion and Muscle Performance in Acute Hypobaric Hypoxia. European Journal of Applied Physiology and Occupational Physiology, 71, 362-368. https://doi.org/10.1007/BF00240418

[3] Oöpik, V., Saaremets, I., Medijainen, L., Karelson, K., Janson, T. and Timpmann, S. (2003) Effects of Sodium Citrate Ingestion before Exercise on Endurance Performance in Well Trained College Runners. British Journal of Sports Medicine, 37, 485-489. https://doi.org/10.1136/bjsm.37.6.485

[4] Miyake, Y., Yamamoto, K., Nagasaki, M., Nakai, N., Murakami, T. and Shimomura, Y. (2001) The Effect of Post-Exercise Lemon Juice and Citric Acid Ingestion on Blood Lactic Acid Concentration in Humans. Journal of Japan Society of Nutrition and Food Sciences, 54, 29-33. https://doi.org/10.4327/jsnfs.54.29

[5] Sugino, T., Aoyagi, S., Shirai, T., Kajimoto, Y. and Kajimoto, O. (2007) Effects of Citric Acid and L-Carnitine on Physical Fatigue. Journal of Clinical Biochemistry and Nutrition, 41, 224-230. https://doi.org/10.3164/jcbn.2007032 
[6] Kajimoto, O., Mieda, H., Hiramitsu, M., Sakaida, K., Yasuda, T., Sugino, T. and Kajimoto, Y. (2007) The Internet Investigation about the Attenuation of Fatigue Feeling by Taking a Drink Containing Lemon Citric Acid. Japanese Pharmacology \& Therapeitics, 35, 821-828.

[7] Kono, R., Nomura, S., Tokuda, A., Okuno, Y., Fujihira, Y., Kamei, I., Nakamura, M. and Utsunomiya, H. (2017) Effects of Citric Acid Oral Intake before Low Intensity Exercise on Blood Lactic Acid and Feeling of Fatigue-A Randomized, Double-Blind, Placebo-Controlled, Cross-Over Study. Japanese Pharmacology \& Therapeitics, 45, 395-403.

[8] Morimoto, K., Komai, M., Osada, K., Tsunoda, K., Suzuki, H. and Furukawa, Y. (1995) Behavioral and Neurophysiological Studies on Preference Changes in Fatigue. Japanese Journal of Taste and Smell Research, 2, S343-S346.

[9] Morimoto, K., Komai, M., Osada, K., Tsunoda, K. and Furukawa, Y. (1996) Studies on Preference Change for Sour Taste Substance in Forced Swimming Load Rats. Japanese Journal of Taste and Smell Research, 3, 616-618.

[10] Saitoh, S., Yoshitake, Y. and Suzuki, M. (1983) Enhanced Glycogen Repletion in Liver and Skeletal Muscle with Citrate Orally Fed after Exhaustive Treadmill Running and Swimming. Journal of Nutritional Science and Vitaminology, 29, 45-52. https://doi.org/10.3177/jnsv.29.45

[11] Underwood, A.H. and Newsholme, E.A. (1965) Properties of Phosphofructokinase from Rat Liver and Their Relation to the Control of Glycolysis and Gluconeogenesis. Biochemical Journal, 95, 868-875. https://doi.org/10.1042/bj0950868

[12] Dunaway Jr., G.A. and Weber, G. (1974) Rat Liver Phosphofructokinase Isozymes. Archives of Biochemistry and Biophysics, 162, 620-628. https://doi.org/10.1016/0003-9861(74)90224-0

[13] Tornheim, K. and Lowenstein, M. (1976) Control of Phosphofructokinase from Rat Skeletal Muscle. Effects of Fructose Diphosphate, AMP, ATP, and Citrate. The Journal of Biological Chemistry, 251, 7322-7328.

[14] Newsholme, E.A., Sugden, P.H. and Williams, T. (1977) Effect of Citrate on the Activities of 6-Phosphofructokinase from Nervous and Muscle Tissues from Different Animals and Its Relationship to the Regulation of Glycolysis. Biochemical Journal, 166, 123-129. https://doi.org/10.1042/bj1660123

[15] Hara, Y. and Watanabe, N. (2013) Effects of Dietary Citric Acid on Metabolic Indicators and Gene Expression in the Skeletal Muscles of Fasted Mice. Food and Nutrition Sciences, 4, 1114-1119. https://doi.org/10.4236/fns.2013.411145

[16] Hara, Y. and Watanabe, N. (2015) Fatigue Alleviation Mechanism of Citric Acid Determined by Gene Expression Analysis in the Mouse Liver. Food and Nutrition Sciences, 6, 1095-1102. https://doi.org/10.4236/fns.2015.612114

[17] de Salles Painelli, V. and Lancha Jr., A.H. (2016) Thirty Years of Investigation on the Ergogenic Effects of Sodium Citrate: Is It Time for a Fresh Start. British Journal of Sports Medicine, 52, 942-943. https://doi.org/10.1136/bjsports-2016-096516

[18] Yasukawa, S., Takamatsu, M., Ebisuno, S., Morimoto, S., Yoshida, T. and Okawa, T. (1985) Citric Acid Metabolism in Urolithiasis 1. Urinary Citric Acid Measurement Using Citrate Lyase. The Japanese Urological Association, 76, 1848-1853.

[19] Yasukawa, S., Ebisuno, S., Morimoto, S., Uehara, M. and Okawa, T. (1991) An Examination of Serum Citric Acid Measurement Using Citrate Lyase. The Japanese Urological Association, 82, 1748-1753.

[20] Livak, K.J. and Schmittgen, T.D. (2001) Analysis of Relative Gene Expression Data Using Real-Time Quantitative PCR and the $2^{-\Delta \Delta \mathrm{C}(\mathrm{T})}$ Method. Methods, 25, 402-408. https://doi.org/10.1006/meth.2001.1262 